\title{
Issues for service providers: a response to points raised
}

Ann Furedi British Pregnancy Advisory Service, London

\begin{abstract}
The issue of abortion has evolved since 1967. In this paper, the shift in the discourses of abortion are discussed. The article suggests that abortion is used as a "back-up" method of family planning and that this is broadly acceptable. Although there is little public opposition to abortion as such, there are influences that undermine abortion provision as it now exists.

Growing concern about the status of the fetus shapes a number of debates. For example the issue of what the

fetus feels during abortion influences abortion practice. Advances in technology and the increase in knowledge about the unborn fetus will not change a woman's decision about having a late termination. The article concludes with the idea that a woman is a moral, civilised human being that deserves the right to make decisions about her reproductive life.

(Fournal of Medical Ethics 2001;27 suppl II:ii28-ii32)
\end{abstract}

Keywords: Abortion; fetus; women; pregnancy; perspective; moral

The abortion discourse has altered fundamentally over recent years. Today it is broadly accepted that abortion has a place in fertility regulation. It is a method of family planning - if by that we mean that women use abortion to control whether, or when, they have children.

Women today expect to have control over their fertility and are expected to control their fertility. The need for "family planning" is almost universally accepted even among the most conservative thinkers. But the evidence shows that women cannot manage their fertility by means of contraception alone. Contraception fails, and couples sometimes fail to use it effectively. A recent survey of more than 2,000 women requesting abortion at British Pregnancy Advisory Service (BPAS) clinics found that almost 60 per cent claimed to have been using contraception at the time they became pregnant; nearly 20 per cent said they used oral contraception. ${ }^{1}$ Other studies have shown similar results. ${ }^{2-4}$

These studies may tend to overestimate the extent of contraceptive failure. Unprotected sex is stigmatised and some women requesting abortion may falsely claim to have used contraception believing they will be treated more sympathetically if the pregnancy is "not their fault". But even so, it is clear that contraceptives let couples down. All methods have a recognised failure rate, and even when the rate is low-as with hormonal contraception - the large numbers of contraceptive users means that the absolute number of failures is high. The failure rate for oral contraception is often cited as around one per cent: with 3.5 million users in Britain that could result in 35,000 unwanted failures simply from the "method failure" of this method alone each year. It seems staggeringly clear to those who work in abortion services that the tens of thousands of women who seek abortion each year are not ignorant of contraception-most have tried to use it and, indeed, may have used it and become pregnant regardless.

Women today are at particular risk of unplanned pregnancy. Sex is an accepted part of an adult relationship for which we do not expect to suffer unwanted consequences. We no longer reserve sex for procreation: sex in the third millennium is for fun. Pregnancy is seen by an increasing number of women as an unwanted consequence to which they are not prepared to adapt. The fact that more women are delaying starting a family until they are in their thirties, that they want fewer children and that many are deciding to opt out of parenthood altogether, suggests increased numbers of sexually active women who want to avoid pregnancy. This need for abortion is implicitly understood by policy makers and legislators, which is why abortion is provided, albeit in a limited way, as part of the National Health Service (NHS).

It is difficult to see how opposition to abortion could be pursued systematically by the establishment at this time. Attitudes to abortion exist as part of a web of other ideas that interface with social values on other issues such as poverty, perceptions of women's role in society, the value of parenting and even global issues such as the environment and "over-population". Distaste for abortion is tempered by the need to engage with these other concerns. For example, most democratic societies hold that women should expect, and be expected, to make a broader contribution to society than bearing and caring for the next generation. Motherhood is still regarded as "natural" at some time in a woman's life, but most people assume that motherhood will be an interval sandwiched on both sides by an income-generating "job" if not a "career". Girls from appropriate (middle-class) backgrounds are expected to progress to a university education. As has been argued, abortion is essential as a "back-up" to contraception if women 
are to exert the required degree of control over their fertility.

Society currently places a high premium on "planned parenthood". The belief prevails that children should be wanted, that parents should be able to support them, and that they should be willing to make sacrifices for them. Growing social concern about "unfit" or "problem" parents does not easily co-exist with a disposition to force people to bear children they do not want and by their own admission cannot care for. This ethos creates a framework whereby abortion can be perceived as a "responsible choice" in some circumstances, even by social conservatives who disapprove of abortion in principle. Indeed, those of us who are genuinely "pro-choice" are sometimes concerned that the establishment may be overly enthusiastic about abortion for welfare-dependent women and teenagers, and that that choice of motherhood is stigmatised or discouraged.

Surveys of public opinion confirm widespread tolerance of abortion. A national opinion poll carried out three years ago by the UK's main polling agency, MORI, found that 64 per cent of those asked agreed that abortion should be legally available to all who want it; 25 per cent disagreed. The remainder neither agreed nor disagreed or said they did not know. The proportion of those who agreed had increased by 10 per cent since $1980 .{ }^{5}$ The Birth Control Trust, a reproductive health advocacy group, for whom the poll was commissioned, suggested this demonstrated a growing acceptance of legal abortion and a widespread belief that the law should not be used to prevent women ending pregnancies.

We may need to reconsider the current tenet of the international family planning community, that abortion should be "safe, legal and rare": if women cannot prevent unwanted pregnancies, then they need to be able to end them. If this is the case, making abortion rare could only be at the expense of women's reproductive choice. Family planning professionals often see a relatively high abortion rate as a sign of the failure of sex education and family planning programmes. It may, however, indicate something more positive: that women wish to combine a sex life with ambition. Increasingly, women may be unprepared to accept an unplanned pregnancy and to shape their lives around it.

Policy makers should stop using the abortion rate as an indicator of a problem. Of course, it is preferable for unwanted pregnancies to be prevented rather than ended. Abortion is safe, but contraception is safer and more convenient. But it may be time to understand that, for women, abortion is an essential method of family planning and to accept it as such.

Abortion is not currently at the forefront of political debate in Britain. While in the USA, and some other countries, such as the North and South of Ireland, abortion remains a hotly contested political issue, in Britain there is less of an open battle between pro-choice and anti-abortion protagonists than at any time in the 30 years since abortion became legal. Occasional protests by antichoice activists at abortion clinics are small and attract little attention. Media coverage is generally far more sympathetic to pro-choice perspectives that to those wishing to restrict the law.

In general, people do not "like" the idea of abortion-but they like the notion of forcing women to have and raise children against their will even less. ${ }^{6}$

The consolidation of public tolerance of abortion has led anti-choice groups to find that they are increasingly marginalised. The Birth Control Trust poll discussed above showed that just two per cent of the population is opposed to abortion in all circumstances. Groups that previously organised to restrict the abortion law have turned their attentions to opposing euthanasia and genetic research-battles they seem to believe are more winnable.

Paradoxically, while there appears to be little enthusiasm for restrictive changes to the abortion law, and indeed a public policy commitment to the provision of services, the continued widespread availability of the procedure up to the legal time limit of 24 weeks gestation is not entirely certain. Indeed it is arguable that abortion provision is being undermined by stealth, and in ways that are not obvious to those who are not involved in delivering or trying to access services. In most areas of the country it has become easier to obtain an abortion before 12 weeks gestation but correspondingly harder to obtain one in later pregnancy. The law may permit abortion at 23 weeks on the same grounds as at eight weeks, but in practice many women will find the upper time limit much lower. There are several reasons for this.

There is a shortage of doctors choosing to specialise in abortion care. Last year, research by the Abortion Law Reform Association suggested that a growing number of trainee doctors were choosing not to participate in the management of abortion, many refusing on grounds of conscience. ${ }^{7}$ Others, who do not have a conscientious objection admit that they try to avoid involvement in abortion because they are intolerant of women who fail to use contraception successfully.

The shortage of abortion doctors particularly affects the provision of later gestation abortions because a growing number of doctors who are comfortable with early abortion decline to provide, or even refer for, later procedures. Many NHS hospitals have established arbitrary time limits of 12 or 14 weeks gestation and are unable or unwilling to manage later gestations. Increasingly, and by default, BPAS seems to be establishing a national specialist role in the provision of later abortions.

Whilst the early abortion of an unwanted pregnancy is broadly accepted, the later abortion of a pregnancy, especially for a more specific reasonsuch as fetal abnormality-is seen as more troubling. Even many pro-choice campaigners have concerns about the clause in the 1967 Abortion Act that allows a pregnancy to be terminated when 
there is serious risk of severe abnormality. The suggestion from disability rights activists that this is "eugenic" and encourages discrimination against people with conditions for which abortion might be performed has affected the views of doctors and the public. Periodically, at doctors' conferences there is debate about whether the conditions for which abortion is permissible should be more clearly defined. Other suggestions, such as the one that women may be attempting to "quality control" their pregnancies, generate comparable controversy. Publicity about requests for "sex-selection" abortions, following the discovery by a pregnant woman that a fetus is "the wrong gender" has provoked some feminist commentators to question whether their support for women's choice can be unconditional.

Additionally, there is an increasing concern about what abortion means for the fetus, especially about what it experiences in later abortion procedures, and whether it is capable of experiencing pain. There is a current debate about the appropriate means of disposal of fetal remains; there is concern to ensure they are treated with dignity and respect.

The practical concerns about the treatment of the fetus during and after abortion provide a striking example of the impact of what appear to abstract ethical concerns about the status of the fetus, the degree to which it is considered sentient, the rights it should or can be accorded, and the respect that is due to it. Although these are old questions that have been debated by philosophers for generations, their centrality to today's debates represent a fundamental change from the dominant discussions of two decades ago (and earlier).

The ethical parameters of the abortion discourse have shifted tremendously. In the 1960s, when abortion was legalised, it was seen as a responsible, moral potential solution to some of the social problems facing those in poverty. Abortion, as it was debated in parliament, was seen as a means to reduce the burden on socially disadvantaged mothers who were unable to cope with large families. In the 1970s the emphasis centred on the status of women. The politics and the ethics of abortion were framed around the social needs of women to be able to participate in society on an equal basis to men. Legal abortion was championed by the women's liberation movement-along with free contraception - as a means for women to be able to control their fertility. ${ }^{8}$ There was little discussion about the rights or status of the fetus.

Today, things are fundamentally changed. The status of women is rarely considered in respect of the ethics of abortion (although it is tacitly understood to underpin the practical need for early abortion): the status of the fetus is the primary concern. Sometimes this is even reflected by women who are themselves considering terminating a pregnancy. Many women are reluctant to give what they perceive to be "selfish" reasons for an abortion. They feel unable to insist that an abortion is needed simply to allow them to maintain a certain lifestyle. Women sometimes tie themselves in knots trying to find justifications for their actions that appear less self interested. Some argue that it would be better for the child if it were not born.

There has been an elevated, quite rarefied discussion about the status of the fetus and the value of fetal life and the respect we can accord it. This sometimes seems polarised between the pro-choice and anti-abortion lobbies. But it need not be.

As a provider of abortion services, our view of the fetus is shaped by the way that a pregnant woman views her condition. Some women view their abortion as simply a means to treat a "late period". Other women, particularly those undergoing the abortion of a previously wanted pregnancy, may identify strongly with the fetus and think of it as an "unborn child". Most women probably fall within these extremes.

Women approach abortion from all manner of perspectives and I believe that, if we have respect for the moral agency of women and if we believe that women can be, and should be, responsible for their decisions, then we must take a lead from them in this matter.

No one is better able to assess her own life circumstances than a woman herself. No one is better able to decide the impact that a child will have on her life, and that of those to whom she is close. It is unbelieveably arrogant for doctors, politicians or policy makers to insist that they should be the arbiters of whether a woman should continue her pregnancy. It implies that women lack the capacity to make rational decisions for themselves. Yet the truth is that a pregnant woman will need to live with the choice she makes for the rest of her life-once made there is no going back. For legislators, regulators, lawyers, and doctors, involvement in abortion is part of working life, for a woman it shapes the rest of her life.

One can accept that the embryo or fetus should be accorded some degree of respect or worth in the abstract that is not due to mere organs or other human tissue, without compromising a commitment to women's reproductive autonomy. The creation of an embryo with its unique capacity to develop into a human being is, in the abstract, aweinspiring and wonderful and worthy of respect. But it is not possible to look at the respect or value that one accords to the fetus in the abstract, in isolation, because the embryo or fetus does not exist in isolation. It is situated in a woman's uterus and is dependent on her for its existence. The issue is not whether it is right or wrong to accord the embryo value as such - but how much respect or value we accord it relative to the respect and value we accord to the woman in whose uterus it develops. The issue is how we balance respect for a potential human life against respect for the autonomy of the pregnant woman in the here and now. This is a premise that affects how we provide services. While there is an interesting discussion to be had about the status of 
the fetus we cannot ignore, as many moral philosophers are prone to do, the status of the woman and our ethical responsibilities to her.

Certain practical issues follow from the discussion of the status of the fetus that have consequences for us as providers and mean that we cannot take an agnostic approach to the fetal-centred debate. There is a danger that by concentrating attention on the fetus, we take our eyes off the woman.

This has already begun to happen in a discussion of the appropriateness of certain abortion procedures. There is a growing discussion in the US, and an emerging one here, about which clinical procedures should be permitted on the basis of how they affect the fetus. Attention in the USA has focused on attempts to ban a particular method of abortion, intact dilatation and extraction, or as the anti-choice lobby describe it- "partial birth abortion". Opponents of abortion object that it is a particularly brutal procedure and should be outlawed. Many states, influenced by sensational descriptions of the procedure, have taken local decisions to prevent doctors using this method. Such laws compromise the clinical freedom of medical professions to act in the best interests of their patients. Abortion is a procedure that is carried out for the benefit of women. We have to face up to the brutal fact that it involves killing a fetus. The end result of an abortion is supposed to be a woman who is not pregnant and a fetus that is no longer alive. If we allow ourselves to be drawn into a debate about the need to modify abortion procedures because of concerns about respect due to the fetus, we will be doing women a disservice. A clinician's concern in abortion should only be to perform the procedure most appropriate to meet the needs of the woman. It would be entirely unacceptable for a doctor's duty to the woman to be in any way compromised by any other concerns.

This principle must also underwrite our response to the emotive discussions about whether the fetus experiences pain. Speculation that the physical development of the fetus may allow it to experience some sensation has formed the basis of objections to later abortions on the grounds that they cause the fetus to suffer. In Britain we benefit from guidance from the Royal College of Obstetricians and Gynaecologists that insists that in gestations of 21 weeks and greater, the fetal heart should be stopped prior to the procedure. ${ }^{9}$ This is sound and sensible advice because it offers comfort to those women who are preoccupied with what their fetus will experience. No doctor wishes to inflict suffering, but it would be wrong to allow the balance of concern to shift from the experience of the woman to the experience of the fetus.

The acceptability of post 20 -week abortions is often scrutinised. Influential columnist and science writer Greg Easterbrook managed to antagonise both pro- and anti-choice lobbies in the USA with an article in The New Republic that argues that scientific advances make the case for liberalising early abortion and restricting late. Easterbrook argues that the case for liberal provision of early abortion is strengthened by evidence that the natural termination of potential life by spontaneous miscarriage is far more common than previously assumed. ${ }^{10}$ But he also claims that discoveries about the brain activity of the more developed fetus stand as an argument against late abortion and should lead us, as John Wyatt argued, for a reduction in the time-limit. ${ }^{11}$ This is not an argument that we should accept.

It is important to defend women's access to late abortion in law and in practice. Women do not request late abortions because they are ignorant of fetal development. Science may now be able to tell us more than ever before about fetal development, and there is clearly much more to learn. But it is arguable whether this is relevant to abortion decisions and whether such decisions will be-or should be-affected by it. Scientists may need high tech developments in fetal monitoring to convince them that the fetus is a complex responsive organism which reacts to its intrauterine environment. The experience of fetal movement has been telling women that for as long as they have been experiencing pregnancy. Nor, in these modern times, are women ignorant of the fact that a developed fetus looks like a small baby.

The few women who request abortions later on in pregnancy do so because they have specific circumstances that drive them to conclude that it is better if their pregnancy does not result in a child. Neither advances in our knowledge of fetal physiology nor the development of fetal medicine and neonatal intensive care will affect these circumstances. The advances described by Professor Wyatt have wonderful implications for those with problem pregnancies where the baby is wanted - but have little relevance to women who feel unable to carry their pregnancies to term. ${ }^{11}$ A woman who feels repulsed by her pregnancy now that she has learnt that her partner is leaving her for another woman is unlikely to be moved by the latest knowledge about fetal development. A woman's personal circumstances are often at the heart of her decision to end a pregnancy. Changed knowledge about the fetus does nothing to change these circumstances.

It has been argued that the approach taken by Easterbrook would benefit more women than it would handicap because if access to early abortion were improved women would not need later procedures except in the hardest of cases. This view is also perpetrated by some UK reproductive health care providers who have been influenced by studies from the early $1980 \mathrm{~s}^{12}$ that highlighted long delays in the abortion referral process and suggested that the number of late abortions could be significantly reduced by improvements in early abortion provision. But that was almost two decades ago. Much has changed, and improved, in the abortion service. Fewer women now face delays and recent work suggests the majority of second trimester procedures could not have been managed earlier. One recent study showed that only 13 per cent of second trimester abortions could have been managed 
earlier by service improvements. ${ }^{13}$ Most women requesting later abortions had not realised they were pregnant, or had denied the pregnancy, or were in circumstances where a wanted pregnancy had become unwanted.

The reasons why women request abortion tend to be marginalised in the abortion discourse. Society tends to see abortion as an abstract issue, a philosophical principle. Those of us who are involved in abortion care have much to contribute to the debate on late abortion because we are uniquely placed to explain why women need access to these procedures. The images of mid-trimester fetuses waved about by the anti-choice campaigners make an impact on the public imagination. They concentrate on what an abortion at this stage does to the fetus; we need to address the issue of why the abortion takes place and what an unwanted pregnancy does to a woman.

Women do not have abortions for abstract reasons or for reasons of principle. Even in countries where women have the right to abortion, they do not exercise that right as they might exercise their right to vote, or to work. They have abortions for the same reason that women have abortions in countries where abortion is illegal. Women have abortions because, for a reason that is compelling to them, the pregnancy is intolerable. This seems an obvious point, but it is often forgotten, particularly in many of the discussions on abortion and fetal abnormality where some disability rights activists claim that such abortions represent eugenic undercurrents in society.

The old feminist slogan, "the personal is political", has a lot to answer for in that it suggests that the way a woman lives her life reflects her political views. This is not an appropriate way to understand individual reproductive decisions, and it is particularly inappropriate in respect of abortion for fetal abnormality. A woman who requests an abortion because she has an abnormal pregnancy does not do so to make a political statement. A termination on grounds of fetal abnormality is not requested because a woman thinks it is wrong for disabled people to be born, anymore than someone who has decided she only wants one child does so to make a statement that large families are wrong. We do not assume that a woman who has a child is making a statement that abortion is wrong. We take our decisions about abortion in the context of our own individual lives. The experience of women who request abortion on grounds of fetal abnormality tells them they cannot, for whatever reason, take on the care of that particular kind of child at that time. Women enter into pregnancy with an image of what motherhood will mean for them and if suddenly the pregnancy doesn't fit into that image then this can throw the entire sense of pregnancy - and their own self identity - out of kilter. We need to understand and respect that.

One of the earlier speakers in this supplement made the point that care for the most vulnerable is a sign of a civilised society. ${ }^{11}$ I would agree with that, but respect for the Kantian imperative that people have value as themselves, and not just as a means to an end, is also a sign of a civilised society. Women must be valued for the people they are and not just for the children they may have.

In his thoughtful exploration of the ethics of life and death, Life's Dominion: an Argument about Abortion and Euthanasia, ${ }^{14}$ Ronald Dworkin argues that the important feature of our culture is a belief in individual human dignity. Central to human dignity is the principle "that people have the moral right - and the moral responsibility - to confront the most fundamental questions about the value and meaning of their own lives for themselves, answering to their own consciences and convictions". This is particularly relevant to decisions about reproduction. A civilised society accepts that women are creatures with a moral conscience who are capable of making responsible decisions for themselves. Abortion can be a responsible, moral choice. Perhaps the most fundamental difference between those of us who support women's right to choose abortion and those who oppose it, is that we trust women to make ethical decisions and to make considered choices-our opponents do not.

Ann Furedi is Director of Communications at British Pregnancy Advisory Service (BPAS), London.

\section{References}

1 British Pregnancy Advisory Service. Contraceptive use by women requesting abortion: a survey by the British Pregnancy Advisory Service. London: British Pregnancy Advisory Service, Oct 1999.

2 Fleissig A. Unintended pregnancy and the use of contraception: changes from 1984 to 1989. British Medical fournal 1991;302:14.

3 Bromham DR, Cartmill RSV. Are current sources of contraceptive advice adequate to meet changes in contraceptive practice? A study of patients requesting termination of pregnancy. British fournal of Family Planning 1993;19:179-83. 4 Murty J, Firth S. The use of contraception by women seeking termination of pregnancy. British fournal of Family Planning

5 A nationally representative quota sample of 1943 adults aged $15+$ from 70 sampling points were interviewed at home. London: MORI omnibus survey, 1997.

6 Furedi A. Wrong but the right thing to do: public opinion and abortion. In: Lee E, ed. Abortion law and politics today. London: Macmillan Press Ltd, 1998: 159-71.

7 Abortion Law Reform Association. Education On termination of pregnancy: doctor's attitudes and experience of abortion. London: Abortion Law Reform Association, 1999.

8 Sheldon S. Beyond control: medical power and abortion law. London: Pluto Press, 1997.

9 Royal College of Obstetricians and Gynaecologists clinical effectiveness unit. The care of women requestiong induced abortion, evidence-based guideline no 7. London: RCOG Press, 2000. (This is due for review in 2003.)

10 Easterbrook G. What neither side wants you to know. Abortion and brainwaves. The New Republic 2000 Jan 31:

11 Wyatt J. Medical paternalism and the fetus. Fournal of Medical Ethics 2000;27(suppl II):ii15-ii20.

12 Clarke L, Farrell C, Beaumont B. Camden abortion study: the views and experiences of women having NHS and private views and experiences of women having NHS and private

13 George A, Randall S. Late presentation for abortion. The Brit-

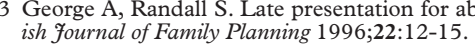

14 Dworkin R. Life's dominion: an argument about abortion and euthanasia. New York: Alfred A Kopf, 1993: 166-7. 